\title{
Photic sneeze reflex: another variant of the trigeminocardiac reflex?
}

\author{
Tumul Chowdhury ${ }^{1}$, Zohara Sternberg ${ }^{2}$, Eugene Golanov ${ }^{3}$, Riccardo Gelpi ${ }^{4}$, Thomas \\ Rosemann ${ }^{5}$ \& Bernhard J Schaller*,5 \\ ${ }^{1}$ Department of Anaesthesiology \& Perioperative Medicine, University of Manitoba, Winnipeg, MB, Canada \\ ${ }^{2}$ Department of Neurology, Buffalo University of New York, NY, USA \\ ${ }^{3}$ Department of Neurosurgery, Houston Methodist Hospital, Houston, TX, USA \& Weill Cornell Medicine, NY, USA \\ ${ }^{4}$ Department of Cardiovascular Pathophysiology, School of Medicine, University of Buenos Aires, Buenos Aires, Argentina \\ ${ }^{5}$ Department of Primary Care, University of Zurich, Zurich, Switzerland \\ *Author for correspondence: bernhardjschaller@gmail.com
}

The photic sneeze reflex (PSR) is a condition of uncontrollable sneezing episodes in response to bright light. This reflex often manifests as a mild phenomenon but may cause devastating consequences in some situations (aeroplane pilots, car drivers, etc.). Its exact mechanism is poorly understood. Interestingly, the roles of the fifth and tenth cranial nerves, brainstem nuclei and inciting patterns closely mimic a wellknown brainstem reflex, known as the trigeminocardiac reflex (TCR). In this critical review, we hypothesize that the PSR can be a variant of the TCR. This concept will lead to a better understanding of the PSR and sharpens the TCR characteristics and open the doors for new research possibilities.

First draft submitted: 26 March 2019; Accepted for publication: 19 July 2019; Published online: 10 October 2019

Keywords: autonomic reflex $\bullet$ brainstem reflex $\bullet$ photic sneeze reflex $\bullet$ trigeminal nerve $\bullet$ trigeminocardiac reflex

The photic sneeze reflex (PSR) is a phenomenon of uncontrollable sneezing episodes following sudden exposure of the sunlight. It is usually a mild reaction, but sometimes imposes significant consequences in particular occupation [1]. The exact mechanism is poorly understood. Various mechanisms have been proposed [2]. Strikingly, roles of the fifth $(\mathrm{CN} \mathrm{V})$ and tenth cranial $(\mathrm{CN} \mathrm{X})$ nerves, brainstem nuclei and inciting patterns mimic another brainstem reflex, known as, the trigeminocardiac reflex (TCR), which is defined as the sudden onset of parasympathetic dysrhythmia, sympathetic hypotension, apnoea or gastric hypermotility during the stimulation of any of the sensory branches of the CN V [3-10]. Recently, it has been highlighted that the TCR phenomenon has a wide array of clinical implications in both experimental and clinical neurosciences [11-22]. Interestingly, recent literature explores the role of the TCR in various conditions, including sudden infant death syndrome, sleep disorders, rhinitis and stroke [23-31].

In this critical review, we hypothesize that the photic sneeze reflex can be a part of the TCR or at least mechanisms of both the reflexes share a common pathway and need to be explored based on existing literature.

\section{The photic sneeze reflex}

The PSR [32] is considered as a condition of uncontrollable repeated sneezing episodes in response to such stimuli as wavelength-independent bright light or periocular (surrounding the eyeball) injection. This condition is also including so-called 'autosomal dominant compelling helio-ophthalmic outburst syndrome (ACHOO)' and affects $18-35 \%$ of the population in the USA [1], but its exact mechanism is not well understood [2]. A recent German study reported much higher (up to 57 percent) prevalence of ACHOO [33]. In general, the PSR seems to be a mild pathophysiological phenomenon. However, more dramatic and severe consequences can develop if PSR occurs in aeroplane pilots or car drivers [1]. The pathophysiology of this phenomenon is still unknown [1].

One hypothesis of the PSR occurrence is based on the crosstalk between the second nerve (CN II) and CN V at the mesencephalon after an intense light stimulation [34]. A second theory called 'parasympathetic generalization' is based on the hypothesis that adjacently located parasympathetic branches are co-activated during the PSR [34] and neurally transmitted to the brain region relevant for the initiation motor execution of a sneeze [34,35]. Other 
Table 1. Similarities between the photic sneeze reflex and the trigeminocardiac reflex (source: own table).

\begin{tabular}{|c|c|c|c|}
\hline Characteristics & TCR & PSR & Synthesis \\
\hline Initiation/triggering & $\begin{array}{l}\text { Sensible CN V; temperature, } \\
\text { mechanical [33-36] }\end{array}$ & $\begin{array}{l}\text { Sensible CN V; temperature, } \\
\text { light, mechanical [35] }\end{array}$ & $\begin{array}{l}\text { The trigger is the same for both reflexes. It is not clear of the light } \\
\text { alone is a factor of PSN, or it is instead the temperature alone }\end{array}$ \\
\hline Symptoms & $\begin{array}{l}\text { CN X; heart (dominant), lung, } \\
\text { stomach [3] }\end{array}$ & $\mathrm{CN} \mathrm{X}$, lung (dominant) $[30,35]$ & $\begin{array}{l}\text { The afferent arc is the same, even the TCR is heart dominant, and } \\
\text { the PSN is lung dominant }\end{array}$ \\
\hline Risk & Cardiac arrest [3] & NA & $\begin{array}{l}\text { The cardiac arrest is an over reaction of the efferent TCR pathways; } \\
\text { for the PSN, nothing similar is described }\end{array}$ \\
\hline Pathophysiology & $\begin{array}{l}\text { CN V, CN X, brainstem [3] } \\
\text { Abnormal medulla } \\
\text { oblongata [57] }\end{array}$ & $\begin{array}{l}\text { CN V, CN X, brainstem [30] } \\
\text { Abnormal medulla } \\
\text { oblongata [58] }\end{array}$ & $\begin{array}{l}\text { Changes in the medulla oblongata may be the basis of both } \\
\text { reflexes }\end{array}$ \\
\hline Genetic & $\begin{array}{l}\text { Polymorphisms and/or mutations } \\
\text { of specific genes [59] }\end{array}$ & $\mathrm{ACHOO}$ syndrome [32] & $\begin{array}{l}\text { In the TCR, there is no genetic syndrome known, even it is a } \\
\text { genetic involvement proposed by serval groups base on } \\
\text { pathoanatomical studies }[3,57] \text {. But a genetic involvement of reflex } \\
\text { occurrence is a substantial part of both reflexes }\end{array}$ \\
\hline Management & Avoidance; atropine $[8,11,13]$ & Avoidance [35] & $\begin{array}{l}\text { Both reflexes do not know an adequate treatment; atropine any } \\
\text { complete protection [6] }\end{array}$ \\
\hline Benefit & $\begin{array}{l}\text { Annoying 'holdover' of } \\
\text { evolution; oxygen conserving } \\
\text { reflex [4] }\end{array}$ & $\begin{array}{l}\text { Annoying 'holdover' of } \\
\text { evolution; protect nasal } \\
\text { respiration [1] }\end{array}$ & $\begin{array}{l}\text { Both reflexes are a holdover of evolution to preserve a sufficient } \\
\text { oxygen supply to the brain }\end{array}$ \\
\hline
\end{tabular}

cases of parasympathetic generalization are already well described as emotional involvement on parasympathetic outflow [36]. A third theory suggests that PSR occurrence is related to a parasympathetic hypersensitivity, particularly within the nasal mucosa [34-36].

\section{The trigeminocardiac reflex}

The TCR was initially defined as "the sudden onset of parasympathetic-sympathetic disbalance, apnoea or gastric hypermotility during stimulation of any of the sensory branches of the CN V" [3]. The generally accepted afferent pathway of the TCR model elucidates that the sensory $\mathrm{CN} \mathrm{V}$ endings send neuronal signals via the Gasserian ganglion to the sensory $\mathrm{CN}$ V nucleus $[4,37-40]$ and continue along the short internuncial nerve fibres in the reticular formation [4,41]. Here, the signals connect with the efferent pathway in the motor branches of CN X nucleus [4,41].

In clinical neuroscience, the TCR has been reported to occur during skull base surgery and in different neurological disorders [5,42-55]. Apart from these numerous clinical reports published during the last 20 years, the physiological mechanisms and function of the TCR have not yet been fully explored, even so, detailed neurobiological studies exist [41]. Probably the most studied particular exemplification of TCR is the so-called diving response [29,56]. Experimental findings demonstrate that the TCR is a coordinated systemic neurogenic reflex integrating central and peripheral mechanisms leading to rapid cerebral vasodilatation, adjustments of parasympathetic and sympathetic activity resulting in changes in blood pressure, redistribution of blood flow, bronchial diameter, mucosal secretion along with changes in cardiac output and plethora of other autonomic changes [5,41]. Specifics of autonomic changes patterns seem to vary depending on the stimuli triggering TCR $[5,41,49]$.

\section{Is the photic sneeze reflex a subtype of the trigeminocardiac reflex?}

There are many similarities between the common origin of PSR and TCR (see Table 1). The CN V initiates both, and both can be induced by temperature and light [1-5]. Both phenomena are triggered by the excitation of the $\mathrm{CN}$ $\mathrm{V}$ [1-5]. Importantly, only sensory branches of the CN V are involved in both reflex pathways.

Studies related to the PSR suggest a cross-talk between the CN II and the CN V that makes the afferent pathways [60]. Some studies suggest that the hypersensitivity of the CN V is a common factor for TCR [3-5] and photic sneeze reflex [1,2]. The brainstem seems to be a plausible site providing the cross-talk between optic input and $\mathrm{CN} \mathrm{V}[32,33]$. At the brainstem, various efferent pathways, including cranial nerves V, VII, IX, XI, XII are interconnected with vagal outflow [10]. Ophthalmic and maxillary branches of the CN V often activate the PSR pathway [1,2], and the TCR can be activated by all the three sensory branches of the CN V [8]. Also, both reflexes are accompanied by parasympathetic over activity [1,5]. These speculations are supported by the observation of similar SR during ocular anesthesia, especially at the light plane, under propofol sedation due to the stimulation of the $\mathrm{CN}$ 
Table 2. Causal relationship in the trigeminocardiac reflex.

\begin{tabular}{|c|c|}
\hline Plausibility & $\begin{array}{l}\text { The appearance of the TCR must be explainable by an adequate stimulation of the trigeminal nerve } \\
\text { The TCR appears promptly after the stimulus is applied }\end{array}$ \\
\hline Reversibility & Stimulus cessation abolishes the reflex, and cardiopulmonary parameters return to baseline \\
\hline Repetition & Reapplication of the stimulus on cranial nerve $\mathrm{V}$ will result in similar hemodynamic changes \\
\hline Prevention & $\begin{array}{l}\text { A lighter stimulus of the same type does not result in the same severe TCR } \\
\text { Trigeminal nerve bock abolishes the TCR } \\
\text { Application of anticholinergic drugs blocks the occurrence of the reflex }\end{array}$ \\
\hline
\end{tabular}

$\mathrm{V}[35,36,60]$. These conjectures are supported by our observations that the light plane of anesthesia is a risk factor for more occurrences of TCR episodes [37,38].

The PSR is also a genetic variant called 'ACHOO' [32]. The abnormal TCR is often postulated to be based on a genetic variance. For an example, the best hypothesis of the pathogenesis of sudden infant death syndrome (SIDS), which is a variant of abnormal TCR, is the so-called 'triple risk model', which suggests that the SIDS is based on interactions of different variables related to exogenous stressors and infant vulnerability [37]. In this context, it is suggested that environmental factors serve as triggers acting during a period of particular sensibility modulated by intrinsic genetic characteristics [37]. While it is undoubtedly true for the SIDS, it may take place in TCR and ACHOO-Syndrome as well. Importantly, tobacco smoking, a risk factor for SIDS [37] is also associated with PSR $[1,2,32,33]$. This view finds additional support in the fact that both phenomena (SIDS and ACHOO) are common in the younger age group [1-5]. Also, the increased parasympathetic tone seems to be a common factor in both conditions [1-5]. Therefore, it is reasonable to suggest that TCR pathways may be indirectly associated with the PSR.

\section{And now what are the consequences?}

The mechanisms of two well-established phenomena are only partially understood. The TCR pathways currently are being a subject of numerous studies. However, the mechanism of PSR remains underinvestigated. On the contrary, triggers initiating the phenomena are better understood in the case of PSR $[1,2,34]$ and only partially for the TCR [3-5]. The basis of both aspects is the CN V with the strong connections to other epiphenomena of the reflex (e.g., 'parasympathetic generalization'). But how can we prove that it is the part of the same reflex arc? There is the need for a causal relationship of the both as described previously for the TCR [55,61].

Plausibility, reversibility, repetition and prevention (see Table 2) - as criterion best established for the TCR [55] (see Table 2) - are also all fulfilled for the PSR and are designed to help clinicians to discriminate better and especially more rapidly between the very nonspecific pain reaction and the more specific TCR reaction. Adequate stimulus like light exposure, physical stimulation of the CN V, various CNS pathologies confirm the plausibility of the PSR [35]. Every stimulus cessation stops the PSR, or repetition of the stimulus leads to the PSR [35]. Therefore, the cause-effect relationship for the PSR is proven. In connection with the above-described connections between TCR and PSR pathways, the PSR and the TCR may be linked. As an inductive consequence of this critical evaluation and a definite causal relation, there can be hypothesized that the PSR is a subtype of the TCR.

\section{Molecular basis}

The molecular mechanisms responsible for TCR and PSR are unknown. Nevertheless, the hemodynamic byproducts of these two reflexes share a resemblance with those of the neurodevelopmental disorder, the Rett Syndrome (RTT). The disease is associated with a variety of autonomic nervous system abnormalities including overactive parasympathetic tone [62], and spontaneous cardiac rhythm abnormalities which may lead to complete cardiac conduction block [63], contributing to sudden death in a quarter of all deaths in RTT individuals [64].

These abnormalities are related to the suboptimal function of the MeCP2 in cholinergic neurons and are partly reversed by atropine [62]. Silencing of MeCP2 early during development result in defects in peripheral innervation of sensory $\mathrm{CN} \mathrm{V} \mathrm{[65],} \mathrm{and} \mathrm{MeCP2} \mathrm{loss} \mathrm{is} \mathrm{associated} \mathrm{with} \mathrm{an} \mathrm{overall} \mathrm{increase} \mathrm{in} \mathrm{neuronal} \mathrm{activity,} \mathrm{especially} \mathrm{in} \mathrm{the}$ area of brainstem with a role in cardiorespiratory function [66].

Whether MeCP2 or allelic variations have a role in TCR or PSR is unknown. However, the increase in neuronal activity is related to the alterations in the activity of several voltage-gated sodium channels [67]. The dysfunction of 
Box 1. Implications for future research.

Parasympathetic generalization

Influence of emotions on TCR

Genetic variant leading to TCR

Data taken from [CHOWDHURY T ET AL., UNPUBLISHED DATA].

TCR: Trigeminocardiac reflex.

some of these channels has also been attributed to the parasympathetic hyperactivity, an electrical malfunction of the ventricles and sudden death in intractable epilepsies [68].

Trigeminal fibers are known to mediate the chemesthetic sensations due to their innervation in the mucous membranes of the nasal cavity, nasopharynx, oral cavity and cornea, through the activation of the transient receptor potential vanilloid 1 (TRPV1) channel [69]. TRPV1 is a multimodal channel, and a member of the transient receptor potential (TRP) family of nonspecific cation channels, whose activation can be the result of a combination of multiple factors [70].

Stimuli such as capsaicin, temperatures above $43^{\circ} \mathrm{C}$ [71] and light [72] can activate these channels through direct stimulation of free CN V fibers endings, suggesting the involvement of these channels in PSR activation. It would be interesting to demonstrate the involvement of these channels in TCR, as additional evidence for the common pathways responsible for the activation of these two reflexes.

Here too, the voltage-gated sodium channels are the main classes of ion channels which underlie the action potential generation and propagation of the TRPV1 of CN V nociceptive neurons, resulting in various sensations including pain in the orofacial area [73]. Nevertheless, the type of the CN V influences the activation of TRPV1 and voltage-gated sodium channels, as $\mathrm{CN} V$ neurons are classified based on cell size, shapes of the action potential, duration of the action potential and isolectin $\mathrm{B}_{4}$ binding sensitivity to tetrodotoxin [74]. The inhibition of TRPV1 and voltage-gated sodium channels are among mechanisms contributing to the analgesic action of the anesthetic eugenol in the orofacial regions [74].

These molecular similarities of RTT and TCR/PSR might help to a better grouping of clinical features of the different known subgroups of the TCR based on molecular differences.

\section{Future perspective}

The hypothesis that the PSR might be a subtype of the TCR has several implications for the TCR/PSR research (see Box 1). Since the beginning of the TCR research nearly 20 years ago, it was postulated that there must be a genetic prerequisite that makes patients prone to the abnormal TCR [10,11]. In case of the specific form of the PSR, ACHOO Syndrome, the hereditary nature is proofed $[1,2,32,33]$. As a consequence, there is an urgent need of a 'risk model' potentially including this genetic prerequisite and helping to further prospectively select those patients in whom and in which severity of the abnormal TCR could occur [75]. As a conceptual innovation of the here presented work, the hypothesis of a multiple risk model of the TCR/PSR occurrence is supported. A genetic involvement explains the fact that individual patients are more prone to the TCR/PSR occurrence than others with the same characteristic. In times of personalized healthcare, such a model is necessary to make the next step in the treatment of the TCR.

The 'parasympathetic generalization' as mentioned for the PSR further supports a cross-classification on different stimuli in certain brain regions providing evidence for a shared neural code for processing specific triggers and underlying an evolutionary significance of the TCR/PSR occurrence.

On the other hand, this possible link between the PSR and the TCR stresses the importance of the TCR again. The TCR is one of the essential protective reflexes [5,21], and its abnormalities might be the cause of various neurological diseases [27,51]. Understanding the mechanisms and functional significance of TCR opens new therapeutic opportunities in clinical neurosciences [51,61], for example, protecting neurons from injury. In this context, a recent Australian work [75] shows that prevention by a remote action (Philtral Pressure Technique) may be successful at least in some cases. This research opens the old question again, whether such manoeuvre could not be used more therapeutically [4].

Besides the previous TCR research, one important point seems that emotions can influence PSR as already described for other autonomous reflexes. This hypothesis might explain why the TCR and its subgroups are better documented during surgery [76-78]. But it also opens the window to further (potential) risk factors [79-81], a better 
understanding of neuroanatomy [82,83] and might explain the influence of positive psychology on the course of different neurological diseases [84-86]. In such a context, the TCR also helps to understand the physiology of the nervous system better and to develop new models of it [87-92].

The more detailed development of diagnostic or treatment strategies must take into account the functional and molecular properties as discussed here and must consider the therapeutic target, brain region, and perhaps cell type or time of application. More directly target therapeutics that are administered as early as possible in the course of the TCR is likely to be the most effective.

\section{Conclusion}

The TCR is a general neural reflex, of which specific appearance and characteristics depend on the particular conditions and triggers. However, more and more clinical and experimental data suggest that there must also be genetic variants that make patients prone to abnormal TCR, which can be dangerous and damaging. Based on a critical literature review and cause relationship, the present hypothesis indicates the possibility that the PSR may be a part of the TCR. Moreover, the existence of the PSR-specific ACHOO syndrome may provide the key to explore the genetic variances underlying the diversity in TCR presentations and supports the concept of a multiple risk model of the TCR/PSR. A fuller understanding of the TCR based on our increasing knowledge of neurobiology together with clinical aspects could lead to effective treatment of TCR/PSR shortly.

\section{Executive summary}

- The trigeminocardiac reflex (TCR) is a well-known brainstem reflex. The photic sneeze reflex (PSR) seems to have some parallels to the TCR so that there is the hypothesis that PSR is a subtype of the TCR.

Photic sneeze reflex a subtype of the trigeminocardiac reflex?

- PSR and TCR have both many parallels which underline the here presented hypothesis that the PSR is a variant of the TCR. Notably, the connection of the PSR to genetic variants highlights the theory that this must also be the case in the TCR. Besides that, the influences of emotions and parasympathetic generalization might be a topic of further research. All in all, the present article underlines the importance of TCR in clinical and basic neuroscience again.

Molecular basis

- Either for PSR nor TCR, there is nothing know about a molecular basis. Here, there is suggested the involvement of cholinergic neurons, voltage-gated channels and multimodal channels based on conceptualization.

Future perspectives

- The better understanding of subtypes of the TCR will lead to a better knowledge of the TCR as there are currently still some blind spots in the understanding of this reflex.

\section{Author contributions}

T Chowdhury developed the hypothesis, assisted substantially in data collection, screening, reviewing, analyzing, contacting the authors, compiling and writing the manuscript. Z Sternberg reviewed and screened the data, and helped substantially in writing the manuscript. E Golanov collected and screened the data and helped in to draft the manuscript. R Gelpi and T Rosemann assisted in writing and editing the paper. B Schaller developed the hypothesis, assisted in writing, reviewing and editing the manuscript.

\section{Financial \& competing interests disclosure}

The authors have no relevant affiliations or financial involvement with any organization or entity with a financial interest in or financial conflict with the subject matter or materials discussed in the manuscript. This includes employment, consultancies, honoraria, stock ownership or options, expert testimony, grants or patents received or pending, or royalties.

No writing assistance was utilized in the production of this manuscript.

\section{Open access}

This work is licensed under the Creative Commons Attribution-NonCommercial-NoDerivatives 4.0 Unported License. To view a copy of this license, visit: http://creativecommons.org/licenses/by-nc-nd/4.0/ 


\section{References}

Papers of special note have been highlighted as: $\bullet$ of interest; $\bullet \bullet$ of considerable interest

1. Breitenbach RA, Swisher PK, Kim MK et al. The photic sneeze reflex as a risk factor to combat pilots. Mil. Med. 158(12), 806-809 (1993).

2. Abramson DC. Sudden unexpected sneezing during the insertion of peribulbar block under propofol sedation. Can. J. Anesth. 42(8), 740-743 (1995).

3. Schaller B, Probst R, Strebel S et al. Trigeminocardiac reflex during surgery in the cerebellopontine angle. J. Neurosurg. 90(2), 215-220 (1999).

-. The first description of the trigeminocardiac reflex is, therefore, a classical work. It is still the standard reference about it.

4. Schaller BJ. Trigeminocardiac reflex. J. Neurol. 251(6), 658-665 (2004).

5. Schaller B, Cornelius JF, Prabhakar $\mathrm{H}$ et al. The trigeminocardiac reflex: an update of the current knowledge. J. Neurosurg. Anesthesiol. 21(3), 187-195 (2009).

6. Tarabanis C, Abt NB, Osborn HA. Intraoperative cardiac arrest etiologies in head and neck surgery: a comprehensive review. Head Neck 40(6), 1299-1304 (2018).

7. Cho JM, Min KT, Kim EH et al. Sudden asystole due to trigeminocardiac reflex during transsphenoidal surgery for pituitary tumor. World Neurosurg. 76(5), 477.e11-5 (2011).

8. Arasho B, Sandu N, Spiriev T et al. Management of the trigeminocardiac reflex: facts and own experience. Neurol. India 57(4), 375 (2009).

9. Shibao S, Kenawy K, Borghei-Razavi $\mathrm{H}$ et al. The trigeminocardiac reflex during the anterior transpetrosal approach. World Neurosurg. 106, 939-944 (2017).

10. Schaller BJ. Trigeminocardiac reflex. J. Neurosurg. 107(1), 243 (2007).

11. Meuwly C, Golanov E, Chowdhury T et al. Trigeminal cardiac reflex: new thinking model about the definition based on a literature review. Medicine 94(5), e484 (2015).

12. Wolf S. Sudden death and the oxygen-conserving reflex. Am. Heart J. 71, 840-841 (1966).

13. Meuwly C, Chowdhury T, Sandu N et al. Definition and diagnosis of the trigeminocardiac reflex: a grounded theory approach for an update. Front. Neurol. 8, 533 (2017).

14. Tamura T, Rex DE, Marosfoi MG et al. Trigeminocardiac reflex caused by selective angiography of the middle meningeal artery. J. Neurointerv. Surg. 9(3), e10 (2017).

15. Duan HZ, Zhang Y, Li L et al. [Trigemino-cardiac reflex in skull base surgery]. Beijing Da Xue Xue Bao Yi Xue Ban 49(1), 164-168 (2017).

16. Cavallo LM, Solari D, Esposito F. Trigeminocardiac reflex: a predictable event with unpredictable aspects. World Neurosurg. 76(5), 407-408 (2011).

17. Crockett MT, Robinson AE, Aneja $\mathrm{H}$ et al. Posterior meningeal artery DMSO injection resulting in reproducible asystole prior to Onyx therapy of a dural arteriovenous fistula: a previously undescribed variant of the trigeminocardiac reflex or a new phenomenon? BMJ Case Rep. 24, 2017: bcr-2017-221033 (2017).

18. Sandu N, Sadr-Eshkevari P, Schaller BJ. Usefulness of case reports to improve medical knowledge regarding trigemino-cardiac reflex in skull base surgery. J. Med. Case Rep. 5(1), 149 (2011).

-. An excellent overview of the topic is showing the difficult way to develop the trigeminocardiac reflex to that what it is now.

19. Mohan S, Flis DW, O'Leary MA. A Case of trigeminocardiac reflex during infrastructure maxillectomy. Nasopharyngeal swelling in a patient with cystic fibrosis following endoscopic sinus surgery. JAMA Otolaryngol. Head Neck Surg. 140(6), 563-564 (2018).

20. Huang JI, Yu HC, Chang YC. Occurrence of trigeminocardiac reflex during dental implant surgery: an observational prospective study. J. Formos. Med. Assoc. 2116(10), 742-747 (2017).

21. Schaller BJ, Sandu N, Cornelius JF et al. Oxygen-conserving implications of the trigemino-cardiac reflex in the brain: The molecular basis of neuroprotection? Mol. Med. 15(5-6), 125 (2009).

22. Haldar R, Gyanesh P, Srivastava A et al. Trigeminocardiac reflex preceding development of postoperative superior orbital fissure syndrome. Asian J. Neurosurg. 12, 116-119 (2017).

23. Schames SE, Schames J, Schames $\mathrm{M}$ et al. Sleep bruxism, an autonomic self-regulating response by triggering the trigeminal cardiac reflex. J. Calif. Dent. Assoc. 40(8), 670-1, 674-6 (2012).

24. Schaller B, Chowdhury T, Rosemann T. The trigeminocardiac reflex: beyond the diving reflex. Front. Neurosci. 11, 673 (2017).

25. Etezadi F, Orandi AA, Orandi AH et al. Trigeminocardiac reflex in neurosurgical practice: an observational prospective study. Surg. Neurol. Int. 18(4), 116 (2013).

26. Haldar R, Gyanesh P, Srivastava A et al. Trigeminocardiac reflex preceding development of postoperative superior orbital fissure syndrome. Asian J. Neurosurg. 12(1), 116-119 (2017). 
27. Chowdhury T, Schaller B. The role of acute trigemino-cardiac reflex in unusual, non-surgical cases: a review. Front. Neurol. 7, 2016 (2016).

28. Livolsi A, Niederhoffer N, Dali-Youcef $\mathrm{N}$ et al. Cardiac muscarinic receptor overexpression in sudden infant death syndrome. PLoS ONE 5, e9464 (2010).

29. Schaller BJ, Filis A, Buchfelder M. Cardiac autonomic control in neurosurgery the example of trigemino-cardiac reflex. Arch. Med. Sci. 3(4), 287 (2007).

30. Lemaitre F, Chowdhury T, Schaller B. The trigeminocardiac reflex-a comparison with the diving reflex in humans. Arch. Med. Sci. 11(2), 419 (2015).

31. He Y, Zhou DB, Wang HW et al. [Clinical analysis of trigemino-cardiac reflex during surgery for patients with skull base tumors]. Zhonghua Yi Xue Za Zhi 93(3), 215-217 (2013).

32. Semes LP, Amos JF, Waterbor JW. The photic sneeze response: a descriptive report of a clinic population. J. Am. Optom. Assoc. 66(6), 372-377 (1995).

33. Kulas P, Hecker D, Schick B et al. Investigations on the prevalence of the photo-induced sneezing reflex in the German population, a representative cross-sectional study. Eur. Arch. Otorhinolaryngol. 274(3), 1721-1725 (2017).

34. Everett HC. Sneezing in response to light. Neurology 14, 483-490 (1964).

35. Brubacker AP. The physiology of sneezing. J. Am. Med. Assoc. 73, 585-587 (1919).

36. Whitman BW, Packer RG. The photic sneeze reflex literature review and discussion. Neurology 43(5), 868-871 (1993).

37. Meuwly C, Chowdhury T, Sandu N et al. Anesthetic influence on occurrence and treatment of the trigemino-cardiac reflex: a systematic literature review. Medicine 94(18) (2015).

38. Dillon M, Power A, Mannion C. Trigeminocardiac reflex. Brit. J. Oral Max. Surg. 55(4), 445-446 (2017).

39. Lübbers HT, Zweifel D, Grätz KW et al. Classification of potential risk factors for trigeminocardiac reflex in craniomaxillofacial surgery. J. Oral Max. Surg. 68(6), 1317-1321 (2010).

40. Joshi UM, Munnangi A, Shah K et al. Trigemino-cardiac reflex: a phenomenon neglected in maxillofacial surgery? J. Max. Oral Surg. 16(2), 181-185 (2017).

41. Buchholz B, Kelly J, Bernatene EA et al. Antagonistic and synergistic activation of cardiovascular vagal and sympathetic motor outflows in trigeminal reflexes. Front. Neurol. 8, 52 (2017).

-• An important overview of the finest manner that is presented about the trigeminocardiac reflex.

42. Schaller B, Sandu N, Filis A et al. Peribulbar block or topical application of local anaesthesia combined for paediatric strabismus surgery. Anaesthesia 63(10), 1142-1143 (2008).

43. Arnold RW, Biggs RE, Beerle BJ. Intravenous dexmedetomidine augments the oculocardiac reflex. J. AAPOS 22(3), 211-213.e1 (2018).

44. Khurana H, Dewan P, Ali $\mathrm{Z}$ et al. Electrocardiographic changes due to vagosympathetic coactivation during the trigeminocardiac reflex. J. Neurosurg. Anesthesiol. 21(3), 270 (2009).

45. Chowdhury T, Cappellani RB, Schaller B. Retrogasserian glycerol rhizolysis: first description of occurrence trigeminocardiac reflex. J. Neurosurg. Anesthesiol. 26(1), 86-87 (2014).

46. Gharabaghi A, Acioly MA, Koerbel A et al. Prognostic factors for hearing loss following the trigeminocardiac reflex. Acta Neurochir. 149(7), 737 (2007).

47. Sandu N, Chowdhury T, Schaller BJ. How to apply case reports in clinical practice using surrogate models via example of the trigeminocardiac reflex. J. Med. Case Rep. 10(1), 84 (2016).

48. Bauer DF, Youkilis A, Schenck C et al. The falcine trigeminocardiac reflex: case report and review of the literature. Surg. Neurol. 63(2), 143-148 (2005).

49. Chowdhury T, Ahuja N, Schaller B. Severe bradycardia during neurosurgical procedure: Depth of anesthesia matters and leads to a new surrogate model of the trigeminocardiac reflex: a case report. Medicine 94(49) (2015).

50. El-Habbash S, Padaki P, Bayoumi $S$ et al. Management of a temporomandibular joint synovial cyst in a case complicated by severe trigeminocardiac reflex. Ann. R Coll. Surg. Engl. 18, e1-e2 (2018).

51. Chowdhury T, Schaller B. The negative chronotropic effect during lumbar spine surgery: a systemic review and aggregation of an emerging model of spinal, cardiac reflex. Medicine 96(1) (2017).

52. Yilmaz T, Erol FS, Yakar $\mathrm{H}$ et al. Delayed trigeminocardiac reflex induced by an intraorbital foreign body. Case report. Ophthalmologica 220(1), 65-68 (2006).

53. Meuwly C, Chowdhury T, Gelpi R et al. The trigemino-cardiac reflex: is treatment with atropine still justified? J. Neurosurg. Anesthesiol. 29(3), 372-373 (2017).

54. Del Seppia C, Ghione S, Foresi P et al. Further evidence of a prolonged hypotensive and a bradycardic effect after mandibular extension in normal volunteers. Arch. Ital. Biol. 154(4), 143-150 (2016). 
55. Meuwly C, Chowdhury T, Gelpi R et al. The clinical surrogate definition of the trigeminocardiac reflex: Development of an optimized model according to a PRISMA-compliant systematic review. Medicine 96(49) (2017).

56. Costalat G, Pichon A, Joulia F et al. Modeling the diving bradycardia: toward an oxygen-conserving breaking point? Eur. J. Appl. Physiol. 115(7), 1475-1478 (2015).

57. Ottaviani G. Defining sudden infant death and sudden intrauterine unexpected death syndromes with regard to anatomopathological examination. Front. Pediatr. 4, 103 (2016).

58. Bernat JL, Suranyi L. Loss of ability to sneeze in lateral medullary syndrome. Neurology 55, 604 (2000).

59. Filonzi L, Magnani C, Lavezzi AM et al. Detoxification genes polymorphisms in SIDS exposed to tobacco smoke. Gene 648, 1-4 (2018).

60. Chen Y, Dammers J, Boers F et al. The temporal dynamics of insula activity to disgust and happy facial expressions: a magnetoencephalography study. Neuroimage 47, 1921-1928 (2009).

61. Chiluwal A, Narayan RK, Chaung W et al. Neuroprotective effects of trigeminal nerve stimulation in severe traumatic brain injury. Sci. Rep. 7, 6792 (2017).

62. Herrera JA, Ward CS, Wehrens XH et al. Methyl-CpG binding-protein 2 function in cholinergic neurons mediates cardiac arrhythmogenesis. Hum. Mol. Genet. 25, 4983-4995 (2016).

63. McCauley MD, Wang T, Mike E et al. Pathogenesis of lethal cardiac arrhythmias in Mecp2 mutant mice: implication for therapy in Rett syndrome. Sci. Transl. Med. 3, 113ra25 (2011).

64. Sekul EA, Moak JP, Schultz RJ et al. Electrocardiographic findings in Rett syndrome: an explanation for sudden death? J. Pediatr. 125 , 80-82 (1994)

65. Leong WY, Lim ZH, Korzh V et al. Methyl-CpG binding protein 2 (Mecp2) regulates sensory function through Sema5b and Robo2. Front. Cell. Neurosci. 9, 481 (2015).

66. Kron M, Howell CJ, Adams IT et al. Brain activity mapping in Mecp2 mutant mice reveals functional deficits in forebrain circuits, including key nodes in the default mode network, that are reversed with ketamine treatment. J. Neurosci. 32, 13860-13872 (2012).

67. Oginsky MF, Cui N, Zhong W et al. Hyperexcitability of mesencephalic trigeminal neurons and reorganization of ion channel expression in a Rett syndrome model. J. Cell. Physiol. 232, 1151-1164 (2017).

68. Kalume F, Westenbroek RE, Cheah CS et al. Sudden unexpected death in a mouse model of Dravet syndrome. J. Clin. Invest. 123, 1798-808 (2013).

69. Bryant BP, Silver W, Restrepo D. Neurobiology of Taste and Smell. Wiley-Liss, Inc., NY, USA 73-100 (2000).

70. Szallasi A, Cortright DN, Blum CA et al. The vanilloid receptor TRPV1: 10 years from channel cloning to antagonist proof-of-concept. Nat. Rev. Drug Discov. 2007(6), 357-372 (2007).

71. Caterina MJ, Schumacher MA, Tominaga M et al. The capsaicin receptor: a heat-activated ion channel in the pain pathway. Nature 389, 816-824 (1997).

72. Saunders CJ, Li WY, Patel TD et al. Dissecting the role of TRPV1 in detecting multiple trigeminal irritants in three behavioural assays for sensory irritation. F1000Res. 2, 74 (2013).

73. Caterina MJ, Gold MS, Meyer RA. Molecular biology of nociceptors. In: Hunt SP, Kolzenburg M (Eds). Textbook of the Neurobiology of Pain. Oxford University Press, Oxford, UK, 12-21 (2005).

74. Park CK, Kim K, Jung SJ et al. Molecular mechanism for local anaesthetic action of eugenol in the rat trigeminal system. Pain 144 , 84-94 (2009).

75. Bobba S, Spencer SKR, Fox OJK et al. Management of the photic sneeze reflex utilising the philtral pressure technique. Eye (Lond.) 33(7), 1186-1187 (2019).

- A nice small work showing the photic sneeze reflex is not a theoretical phenomenon but also has great practical relevance.

76. Gorini C, Philbin K, Bateman R et al. Endogenous inhibition of the trigeminally evoked neurotransmission to cardiac vagal neurons by muscarinic acetylcholine receptors. J. Neurophysiol. 104, 1841-1848 (2010).

77. Gorini C, Jameson HS, Mendelowitz D. Serotonergic modulation of the trigeminocardiac reflex neurotransmission to cardiac vagal neurons in the nucleus ambiguous. J. Neurophysiol. 102(3), 1443-1450 (2009).

78. Gorini C, Jameson $\mathrm{H}$, Woerman AL et al. Prenatal nicotine exposure enhances the trigeminocardiac reflex via serotonin receptor facilitation in brainstem pathways. J. Appl. Physiol. (1985) 115(4), 415-421 (2013).

- Excellent work is showing that we need to better understand the biochemistry to improve our knowledge of the trigeminocardiac reflex.

79. Mehboob R. Substance P/Neurokinin 1 and trigeminal system: a possible link to the pathogenesis in sudden perinatal deaths. Front. Neurol. 8, 82 (2017).

80. Woerman AL, Mendelowitz D. Perinatal sulfur dioxide exposure alters brainstem parasympathetic control of heart rate. Cardiovasc. Res. 99, 16-23 (2013). 
81. Panneton WM, Anch AM, Panneton WM et al. Parasympathetic preganglionic cardiac motoneurons labelled after voluntary diving. Front. Physiol. 5, 8 (2014).

- Important work is shedding light on the neuroanatomical basis of the trigeminocardiac reflex.

82. Panneton WM, Pan B, Gan Q. Somatotopy in the medullary dorsal horn as a basis for orofacial reflex behaviour. Front. Neurol. 8,52 (2017).

83. Panneton WM, Gan Q, Ariel M. Injections of algesic solutions into muscle activate the lateral reticular formation: a nociceptive relay of the spinoreticulothalamic tract. PLoS ONE 10(7), e0130939 (2015).

84. Wang SB, Wang YY, Zhang QE et al. Cognitive behavioural therapy for post-stroke depression: a meta-analysis. J. Affect. Disord. 235, 589-596 (2018).

85. Lai ST, Lim KS, Tang V et al. Positive psychological interventions for people with epilepsy: an assessment on factors related to intervention participation. Epilepsy Behav. 80, 90-97 (2018).

86. Chen T, Peltola MJ, Dunn R et al. Modulation of the eyeblink and cardiac startle reflexes by genuine eye contact. Psychophysiology 54(12), 1872-1881 (2017).

87. Costalat G, Coquart J, Castres I et al. The oxygen-conserving potential of the diving response: a kinetic-based analysis. J. Sports Sci. 35(7), 678-687 (2017).

88. Al Haddad H, Laursen PB, Chollet D et al. Effect of cold or thermoneutral water immersion on post-exercise heart rate recovery and heart rate variability indices. Auton. Neurosci. 156(1-2), 111-116 (2010).

89. Costalat G, Lemaitre F, Tobin B et al. Intermittent hypoxia revisited: a promising non-pharmaceutical strategy to reduce cardio-metabolic risk factors. Sleep Breath. 22(1), 267-271 (2018).

90. Scharbarg E, Daenens M, Lemaitre F et al. Astrocyte-derived adenosine is central to the hypnogenic effect of glucose. Sci. Rep. 12(6), 19107 (2016).

91. Meuwly C, Leibundgut G, Rosemann T et al. Sinus arrest with prolonged asystole due to the trigeminocardiac reflex during application of local anaesthetic in the nasal mucosa. BMJ Case Rep. pii:bcr-2018-226427 (2018).

92. Sternberg Z, Schaller B. Central noradrenergic agonists in the treatment of ischemic stroke: an overview. Transl. Stroke Res.(2019) (In press). 